\title{
Designing effective healthcare quality improvement training programs: Perceptions of nursing and other senior leaders
}

\author{
Sarah C Blake, Susan S Kohler, Steven D Culler, Jonathan Hawley, Kimberly J Rask \\ Rollins School of Public Health, Emory University, USA
}

Correspondence: Sarah C Blake. Address: Emory University, Rollins School of Public Health, 1518 Clifton Road, NE, \#672, Atlanta, Georgia 30322, USA. Telephone: 404-712-9713. Email: scblake@emory.edu.

Received: June 15, 2012

DOI : $10.5430 /$ jnep.v3n5p66
Accepted: August 24, $2012 \quad$ Online Published: December 11, 2012

URL: http://dx.doi.org/10.5430/jnep.v3n5p66

\section{Abstract}

Objective: This study focused on best practices for designing effective quality improvement (QI) training programs for nursing leaders and other senior leaders in a health care organization.

Background: Leadership models for quality improvement in healthcare are underdeveloped. Challenged by a wide range of professional roles and responsibilities, nursing leaders are less likely than health professional trainees to have formal training in QI or patient safety. We highlight the experiences that nursing leaders, as well as other senior leaders, from a large health care organization had in participating in a quality improvement training program.

Methods: Qualitative methods were used to assess senior leaders' perceptions and recommendations for creating effective QI training programs. Semi-structured interviews with nursing leaders and other senior health care leaders were conducted to explore participants' experiences with the training program and their perceptions about whether information gained from the program has the potential to transfer into clinical practice. Participants' pre and post course knowledge tests were also analyzed to assess overall QI knowledge improvement.

Results: Findings suggest that QI knowledge gains for nursing leaders and others were strongest for vocabulary and major concepts, as well as specific QI tools. Additionally, nursing leaders overwhelming appreciated the opportunity to design a QI project, where learning how to write a proper aim statement, was among the biggest benefit to this exercise. Participants in the QI course felt that it was a good investment of their time. The training program also served as a helpful reminder of the importance of quality improvement as well as an awareness of the organization's commitment to it. Nursing leaders recommended that QI training programs be tailored to their level of existing QI knowledge, their availability and preferences for learning styles, as well as interest in translating QI projects to practice for the purpose of sustaining QI interventions.

Conclusions: The findings from this research provide strong evidence that senior QI leadership training programs are important investments for health care organizations. Results indicate that nursing leaders and others in leadership positions can be effectively trained, become very knowledgeable about QI terms and skills, and apply these skills to support staff initiatives to improve outcomes.

\section{Key words}

Nursing leadership, Health care quality improvement, Quality improvement training, Qualitative research 


\section{I ntroduction}

Training programs have been common strategies employed by organizations to teach quality improvement (QI) to health care professionals, especially to nursing leaders. Such efforts have often focused on ways to promote experiential learning and the transfer of such knowledge to practice ${ }^{[1-3]}$. Studies indicate that clinically focused QI training can improve patient safety and reduce inefficiency ${ }^{[4-7]}$. However, a recent systematic review of clinically-based QI training programs found while leading to improvements in learner knowledge, the impact of QI training programs on clinical outcomes is unknown ${ }^{[8,9]}$.

Leadership models for quality improvement in healthcare are underdeveloped. Challenged by a wide range of professional roles and responsibilities, nursing leaders and others in leadership positions are less likely than health professional trainees to have formal training in QI or patient safety ${ }^{[10,11]}$. And while many leaders, particular physician and nursing leaders, are experts in their fields, they lack experience in implementing QI initiatives ${ }^{[12,13]}$. Traditionally, healthcare QI training programs are aimed at preparing medical residents in quality improvement and patient safety ${ }^{[14-19]}$. However, recent QI training programs have focused on nursing leadership development and proficiency in QI ${ }^{[20-25]}$.

In this article, we highlight the experiences that nursing leaders and other senior leaders from Emory Healthcare (EHC) had in participating in a quality improvement training program. This program, known as "Leadership for Healthcare Improvement," is a two-day program designed to teach senior leaders the vocabulary and skills required to execute, support and coach process improvement efforts driven by their employees. Senior EHC nursing leaders and other participant leaders provided their assessment of the course through in-depth interviews. Course satisfaction, skills gained, and ability to successfully engage and support QI initiatives were the major constructs addressed through these interviews. Based on their insights, nursing leaders and other participants of the Leadership course provided helpful recommendations about how best to design effective quality improvement training programs for senior leaders.

\subsection{Aims of the study}

The aims of this study were to: a) examine best practices for designing effective QI training programs for nursing and other senior leaders in a large health care organization; and $b$ ) assess whether and to what extent nursing leaders and other senior leaders learned and applied new QI skills gained through the EHC QI training program.

\subsection{Background of the leadership course}

The Leadership course is offered over two days through Emory Healthcare (EHC), a large, urban academic health care system that incorporates five hospitals and a multispecialty physician practice. Taught primarily by the Chief Quality Officers at EHC's two core hospitals, the course also includes guest lectures by health care administrators, professional staff, and faculty across the healthcare system. The Leadership course incorporates several teaching methods including lectures, group discussion, and Q\&A sessions with EHC executives and examines topics such as public reporting of quality data and public accountability, quality measurement and management based on data, human factors and reliability science, health care processes, tools of process management, management of process improvement, fair and just culture, systems thinking and roles of leadership. A total of 545 senior leaders took part in one of nine courses offered between January 2008 and November 2009. Approximately one quarter of these senior leaders were nurses.

\section{Methods}

\subsection{Study design}

Semi-structured interviews with a sample of participants from each QI training program were conducted to explore participants' experiences with the training program and whether information gained from the program had the potential to transfer into clinical practice. Two study staff members conducted interviews lasting 30 to 45 minutes. Participants were 
interviewed either face-to-face or by telephone depending on participants' preferences. Interviews were digitally audiotaped and transcribed to ensure that the information was complete and accurate. Efforts to ensure quality of the analysis included using respondent validation through these use of member checks via narrative feedback during the interviews to

verify information ${ }^{[26]}$. In addition to the interviews, we analyzed the pre and post course knowledge tests of our study participants. The purpose of this analysis was to assess overall gains in QI knowledge before and after taking the Leadership course. The study received appropriate human subjects approval from Emory University's Institutional Review Board. Participation in this study was voluntary and all data were kept confidential.

\subsection{Survey participants}

Senior leaders attending each of the nine classes were grouped into three baseline knowledge strata (high, medium, low) based on their performance on a pre-training knowledge assessment. This strategy was implemented to minimize bias by ensuring that high performing participants were not oversampled and that we recruited along the entire spectrum of baseline QI knowledge. We randomly selected three potential candidates from each performance stratum, and from each class ( 9 per class $\times 9$ classes) and solicited their participation. Eighty-one (81) potential candidates were contacted by email, of these 29 (29/81, 35.8\%) agreed to be interviewed. Interviews were conducted between June 2009 and May 2010.

\subsection{I nterview guide}

The interview guide was developed by the study team and reviewed by a qualitative research expert. A systematic literature review formed the basis for the questions that contained both open-ended and semi-structured questions. The questionnaire consisted of seven constructs, with 33-items contributing to the constructs as follows:

- Six items describing the participant's background and experience in QI training.

- Nine items assessing the participant's perception of the program and its effect on job performance.

- Three items assessing the participant's understanding of the program objectives and whether the objectives were met.

- One item assessing the participant's confidence in creating a fair and just culture.

- Seven items assessing the participant's change in knowledge and/or proficiency.

- Four items assessing perceived long-term impact of the program.

- Three items assessing perceived organizational support for quality of care initiatives.

For the benefit of refining our data collection efforts, both in content of the data and procedures to be followed, pilot testing consisted of conducting one-on-one interviews with four program participants. The interview responses were not included in the study sample but provided the interviewers with an opportunity to review and revise the questions.

\subsection{Analysis}

Following traditional principles of grounded theory by which themes or codes emerge from the narratives of the research participants, two research team members carried out inductive analysis ${ }^{[27,28]}$. After transcripts were de-identified, they were independently reviewed by the two research team members, who met several times to discuss initial themes and codes. A draft codebook was developed and used as a basis for further exploration of themes. To finalize the codebook, we used constant comparison, a common principle of grounded theory data analysis, whereby there is an iterative cycle of data collection, analysis, and comparison with previously collected data. This approach was used until unifying and recurrent themes emerged from the data and no new codes could be produced ${ }^{[29,30]}$. Discrepancies in coding were resolved by discussion until consensus was reached. MaxQDA 10, a qualitative software program for managing qualitative analysis, facilitated data organization, management, and retrieval ${ }^{[31]}$. 


\section{Results}

\subsection{Respondent characteristics}

Ten of the interview participants were nurses (10/29, 34.5\%), two were physicians (2/29, 6.9\%), and one was a physician assistant (1/29, 3.4\%). The degree status of the remaining 16 participants (16/29, 55.1\%) was unknown. However, of the 29 interviewees, most held positions as administrators (18/29, 62.1\%), while five were senior leaders affiliated with medical departments $(5 / 29,17.2 \%)$, three with surgical departments $(3 / 29,10.3 \%)$, and three worked in hospital based clinical services (3/29, 10.3\%). Also, most interviewees had some prior QI training (20/29, 69.0\%). Of the ten nurse leaders who participated in our study, seven has prior QI experience. Four of the ten nurse leaders worked in administration, two with surgical departments, three in medical departments, and one in hospital based clinical services. Table 1 provides the characteristics of all study participants.

Table 1. Demographic Characteristics of Leadership Participants ( $\mathrm{N}=29)$

\begin{tabular}{lll}
\hline Item & $\#$ & $\%$ \\
\hline Degree Status & 10 & 34.5 \\
RN/RN+ & 2 & 6.9 \\
MD & 1 & 3.4 \\
PA-C/MBA & 16 & 55.1 \\
None/Unknown & & \\
Department Affiliation & 18 & 62.1 \\
Administration & 5 & 17.2 \\
Medicine & 3 & 10.3 \\
Surgery & 3 & 10.3 \\
HBCS & & \\
Prior QI Training & 20 & 69.0 \\
Yes & 9 & 31.0 \\
No & &
\end{tabular}

\subsection{Major themes}

Based on the experiences of participants in our study, several major themes emerged that describe recommendations for designing effective quality improvement training programs for senior leadership. These themes are described under the follow four major domains: pre-course QI knowledge assessment, course structure, course curriculum, and instructor feedback/involvement.

\subsubsection{Pre-Course QI knowledge assessment}

Findings suggest that QI training programs for nursing leaders and other senior leaders should incorporate a pre-course assessment of QI skills and knowledge. Participants in our study had varying levels of quality improvement knowledge and experience. Some participants felt the course was a review and did not add to their level of QI knowledge, while others expressed gratitude for learning new QI tools.

One nursing leader felt the training program provided her the opportunity to gain more experience with a QI tool and also to learn a new one.

I did get more information on LEAN than I had in the past. I had never worked with the five S's. I had heard of it but going in detail really did help. I had never really truly worked with anything involving Six Sigma...you know I had worked with LEAN and other things but not done a lot of Six Sigma information. So it clarified some of that and was a review for some other pieces of it. 
Yet, for another participant who had in-depth prior QI experience and knowledge, the course was simply a review and not instructive overall.

..it was painful to have to sit through two full days of review and material.... There was no new information for me. It was interesting, and I put this on my little background sheet, but for someone who's already at a high executive level...... having implemented all of these programs at another place it would have, there was just nothing new I guess... I was happy to see Emory was moving in this direction....But for coming from another local hospital it was actually kind of old news.

Developing competency in quality improvement has been linked in training programs to the ability of course designers to adapt to the varying level of QI knowledge and skills among the students ${ }^{[32]}$. During our interviews, participants were asked to assess their level of knowledge before and after taking the course on a scale of 1 to 5 , with a "1" indicating a novice or little to no knowledge or skill and a "5" indicating an expert level of knowledge such that the participant understands the topic, can apply it and could train others in it. They were asked to rate the following 7 topics: 1) ability to engage in quality improvement activities including patient safety initiatives; 2) ability to establish an active, effective quality management committee with clear focus and objectives; 3) ability to write a proper aim statement; 4) ability to select an appropriate metric; 5) ability to model a process with flow charts; 6) ability to identify opportunities for improvement with a cause and effect diagram and Pareto chart; and 7) ability to plan a PDSA cycle

As Table 2 reflects, most participants reported having more of a novice QI level of knowledge before taking the course. However, after taking the course, the level of knowledge increased. For all participants, the biggest gain in QI knowledge was in ability to write a proper aim statement $(+1.4)$, with a second highest gain in the ability to plan a Plan Do Study Act (PDSA) cycle (+1.2). Fewer participants gained new knowledge with flow charts to model processes $(+.9)$, though as the data reflect, participants had a higher beginning knowledge of flow charts than any of the other QI measures. Nursing leaders reported the biggest gain in QI knowledge among all participants in the ability to write a proper aim statement $(+1.6)$. They measured equally with a second highest gain in both the ability to select an appropriate metric and the ability to plan a PDSA cycle (+1.4). Nursing leaders also reported big improvements in QI knowledge in the ability to establish an active, effective quality management committee $(+1.3)$ and in the ability to engage in quality improvement activities $(+1.2)$.

Table 2. Change in Knowledge \& Skills , By Prior Knowledge

\begin{tabular}{lllll}
\hline Change in Knowledge/Skill & All & All Participants & $\begin{array}{l}\text { Nursing } \\
\text { Leaders }\end{array}$ & $\begin{array}{l}\text { Nursing } \\
\text { Leaders }\end{array}$ \\
\hline Item & Mean & Mean & Mean & Mean \\
(1=Novice, 5=Expert) & Pre-score & Post-score & Pre-score & Post-score \\
\hline Change in Knowledge: QI Engagement & 2.7 & 3.8 & 2.6 & 3.8 \\
Change in Knowledge: Committee & 2.5 & 3.5 & 2.3 & 3.6 \\
Ability to Write Proper AIM statement & 2.7 & 4.1 & 2.1 & 3.7 \\
Ability to Select Appropriate Metric & 2.9 & 3.9 & 2.3 & 3.7 \\
Ability to Model Process with Flow Charts & 3.1 & 4.0 & 2.6 & 3.5 \\
Ability to Identify Improvement with Cause \& Effect / & 2.6 & 3.6 & 2.2 & 3.2 \\
Pareto Chart & 2.7 & 3.9 & 2.4 & 3.8 \\
Ability to Plan a PDSA Cycle & & & \\
\hline
\end{tabular}

As condition of their participation in the course, participants completed a pre- and post-training knowledge assessment, which consisted of 15 questions addressing quality care definitions and 15 questions addressing quality care concepts. Table 3 indicates a significant increase in QI vocabulary despite the majority having reported previous QI training. Post-course knowledge scores were markedly higher, with $79.3 \%$ of informants receiving a score of 20 or greater, compared to only $13.8 \%$ of informants scoring a 20 or above who took the pre-course knowledge test. Nursing leaders 
experienced the greatest gain in QI knowledge, with 80\% receiving a score of 20 or greater in the post-course knowledge test, compared to $78.9 \%$ of non-nurses. In addition, the gains were significantly higher for nurses, since only $10 \%$ received a score of 20 or above on their pre-course knowledge test, compared to $15.8 \%$ of non-nurses.

Table 3. Knowledge Test Results

\begin{tabular}{|c|c|c|c|c|c|c|}
\hline \multirow{2}{*}{ Knowledge Test (Out of 30 Questions) } & \multicolumn{2}{|c|}{ Overall $(\mathrm{N}=29)$} & \multicolumn{2}{|c|}{ Nurses $(\mathrm{N}=10)$} & \multicolumn{2}{|c|}{ Non-Nurses $(\mathrm{N}=19)$} \\
\hline & $\#$ & $\%$ & \# & $\%$ & $\#$ & $\%$ \\
\hline $\begin{array}{l}\text { Number of Participants Who Scored a } 20 \text { or } \\
\text { Higher on Pre-Test (Mean Score 14.7; Range } \\
\text { 5-21) for overall column }\end{array}$ & 4 & 13.8 & 1 & 10.0 & 3 & 15.8 \\
\hline $\begin{array}{l}\text { Number of Participants Who Scored a } 20 \text { or } \\
\text { Higher on Post-Test (Mean Score 24.3; Range } \\
\text { 15-30) for overall column }\end{array}$ & 23 & 79.3 & 8 & 80.0 & 15 & 78.9 \\
\hline
\end{tabular}

\subsubsection{Course structure}

Results from the interviews suggest that QI training programs for nursing leaders should be designed with enough flexibility to reflect not only the prior QI knowledge of the participant, but also to allow time to complete quality improvement assignments or projects. Participants in this study felt that several structural elements of the QI training limited their experience, including the short timeframe of the course (i.e., 2 days), the large amount of information, and general pace of the class.

Other participants suggested that refresher, or "booster" sessions could be added to the Leadership course to sustain the knowledge gained from the 2-day course.

Some follow-up would be wonderful so that, you know, here's a great opportunity to continue that engagement of people that they bring into that Academy instead of just letting them you know be on their own. I mean...it's a good course, and I think it's something they need to continue...I think they need to better close the loop and follow-up.

Participants were encouraged, though not required, to design a project incorporating learning objectives from the course. Specifically, participants were asked to develop an aim statement, a description of the proposed project, identification of an appropriate metric, and an assessment of potential challenges to implementation. A major discussion during most interviews was about the course QI project. Almost all participants (27/29, 93.1\%) completed the QI course project. A majority also believed that the project was instructive (22/29, 75.9\%). One senior nurse who leads a surgical unit indicated that learning root cause analysis through the course helped her complete as well as sustain her QI project.

I think some of the things it really helped was, is understanding things like root cause analysis and understanding that this is not a punitive process. We've done a root cause analysis with an issue at [unit] since we opened and I think having done the quality academy, having done, worked on a couple of root cause analysis projects, that ...is all kind of related to that also in that fair and just culture. That I think it really did help me be able to be a, not just a, a listener but a participant in those processes.

However, there were several comments about the challenges of finishing the project, given the respondents' job responsibilities and limited course instruction related to the project. One nursing leader who had no prior QI training expressed her frustration with the length of the course and her inability to complete the required QI project as a result.

For myself, not having any other prior quality experience and always wanting to learn something new, I would have wished that it would have been longer or more detailed in terms of the information they were giving out.. even though it was two full days, it was so much information to learn and, you know, to me, thinking it was quality 
and so much, so many of us were going to, that obviously it was something we needed to learn. But one day we're doing this, we're talking, they're talking all day and then day two we're talking and then we have a project, that's it. I said, project? What did we learn that we can do this big project?

In addition to providing enough time to complete QI projects, course developers also have to structure sessions to meet the needs of an interdisciplinary mix of senior leader attendees. Participants in the Leadership course included a mix of senior leaders from various clinical and non-clinical departments within EHC. Nursing leaders in particular were favorable about the interdisciplinary nature of the course, noting that this design element may have contributed to better QI learning. One nursing leader expressed gratitude for the opportunity the training program gave her to gain a new perspective about quality improvement.

I spend most of my working life with a bunch of nurses and I love having another perspective on people that work in the Emory clinic or people that work at the university and who don't do nursing. Because it brings another flavor and a dimension and it helps me think of things not with a nurse's eyeglasses on so to speak.

Some senior leaders appreciated the interdisciplinary nature of the course simply for the opportunity to meet new EHC employees and to learn more about what others do within the health care system. One nursing leader explained her view:

I think it was extremely helpful because people do things in different areas that you think, oh, you find out that there are ways to do things outside of your area.

Another participant expressed a similar reaction to the interdisciplinary design of the QI training program.

I thought it was particularly interesting when [the instructors] would engage the crowd and kind of ask people what problems they've had or what they're looking to improve. Because you got a sense, you know, that HR has its own deal and you didn't, you got a little information on how that operates or how the [Clinic], which I interact, you know, with quite often, how, you know, they got their own bugs that they're working on. So it was kind of good, especially when [an instructor] was engaging the audience and having people share their stories because it was very fascinating to see kind of what, what happened and how, you know, leaders in different positions, non-MD positions as well, kind of conduct business.

\subsubsection{Course curricula}

Participants indicated that a major benefit to taking the Leadership course was the acquisition of new QI knowledge. Most of the leaders felt that exposure to common QI vocabulary and terms were beneficial. "The glossary, process terms, and some of the information that we got throughout the two days has been very helpful with me on the job.” One nursing leader who works in administration explained why having this new knowledge was important to her:

I think that course was very good because it, it actually took you from the very beginning, from step one, to the terminology and the history. I thought that was very important because without that foundation, it's pretty hard to say you're going to jump into a project and do, you know, do a quality improvement project if you don't really understand what you're doing.

Participants in our study were asked to rate the top three methods for teaching QI. The options were: 1) presentations/ lectures; 2) case-based learning; 3) small group discussions/ brainstorming sessions; 4) panel discussions and 5) the individual group project. Twenty-eight of the twenty-nine participants responded, indicating that the two most preferred QI teaching methods were presentations/lectures (22/28, 78.6\%) and case-based learning (22/28, 78.6\%). There was an equal number of participant who ranked small group discussion/brainstorming sessions and the individual group project as the third most effective teaching method (16/28, 57.1\%) Almost all the nursing leaders listed presentations/lectures (9/10) 
and case-based learning (8/10) as their top two preferred QI teaching methods. Table 4 provides the results from all training program participants.

Table 4. Most Effective Teaching Methods

\begin{tabular}{lll}
\hline Top 3 Teaching Methods & $\#$ & $\mathbf{\%}$ \\
\hline Presentations / lectures & 22 & 78.6 \\
Case-based learning & 22 & 78.6 \\
Small group discussions / brainstorming sessions & 16 & 57.1 \\
Individual group project & 16 & 57.1 \\
Panel discussion & 8 & 28.6 \\
\hline
\end{tabular}

Responses from participants during the interviews further elaborated why these methods were chosen as the most effective for teaching QI. One senior nurse leader explained why case based learning is effective. "I love case based learning. I mean, they stick in my mind when you can relate it to actual experiences.” Another nursing leader who works in clinical services described why she prefers presentations as a QI teaching method.

"it kind of gives you the framework and then gives you the chance to ask any questions. Because I'm, I'm a very visual person. So, being able to look at it and then have the resources in front of me helps me to understand and, and learn better."

\subsubsection{Instructor feedback \& involvement}

A final theme that emerged from this study is that the QI course instructors should play an active and on-going role in shaping the experiences of QI course participants. Overall, participants were pleased with the course speakers, indicating that the type of instructor influences the value placed on the training by participants. One participant noted:

They had various speakers of the present leadership...and they gave us a lot of information about the Emory Mission and you know transparency...so that you got more of an in-depth knowledge you know of what they're trying, for the leaders to emulate and influence you know as you work with your own people.

The course participants, while pleased in general with their QI project assignments, were disappointed that they did not receive feedback from the instructors after turning in their projects. Many senior leaders in the course indicated that knowing how well they did or what needed improvement would have been helpful.

I mailed it in and I haven't heard anything since. It would've been nice to see you know how I could have done it better. Or things that were missing from it. No. I mean they said that this was required for graduation, but I don't know if I graduated.

Another respondent who did receive notice that he graduated felt still that more feedback about the project was warranted.

It was a requirement and it almost felt like just a, a requirement for requirement's sake. And I know the intent, I'm sure the intent was to help you learn and apply some of the things you, you were exposed to in the seminars but it, you know, I guess, I guess I would have liked to have had a little more feedback .. If somebody looked at it. And it was so simple, I mean it was, maybe too hard, too hard to critique it, it was so simple. But to say, you know, you're onto a good idea there, why don't you consider doing this and or but, or you missed the point. Why didn't you consider, you might have considered this. Didn't get any of that kind of feedback... So I'm assuming it was just fine. .. It was more of an exercise.

Others felt that course instructors needed to allow for more time to clearly explain the QI project and to allow participants to ask questions about it. One participant did not have enough time to really understand and think through the assignment. 
It's [the course] two days. So if there's somewhere a little bit earlier in day two. I mean, it just didn't leave much time for the, the project explanation...And I think since people have to turn it in and everything, if that could come a little earlier in day two, a little bit earlier where people have enough time... To think about it and ask questions and get a little more direction before they leave and they're just off.

On a more positive note, respondents felt that taking part in the QI training program enabled them to transfer their knowledge to others in their workplace. Specifically, nursing leaders, especially those with prior QI training, reported that they are able to teach others about QI as a result of participating in the course. One nursing leader who reported a big gain in QI her ability to teach QI shared her experience teaching her nurses.

I've been able to teach them by showing the process, what we're trying to accomplish, giving them the feedback and helping them to, or being open to accepting their recommendations for tests of change to improve. And always say that we're going to do this in a process, this is a process.

One nurse leader however, still feels she needs more training before being able to teach others about quality improvement. She has no prior QI experience before taking the course.

I still feel that I'm a novice and I'm gaining experience. I don't think I'm at that point. But certainly team up with someone else, you know, at any level and, and be able to hopefully contribute. But I don't, I don't feel like I have a mastery enough to teach it.

\section{Discussion}

The main purpose of this study was to assess the best practices for designing effective quality improvement training program for nursing leaders and other senior leaders enrolled in a QI leadership training program at a large health care organization. This study results yielded several important lessons and recommendations for future QI training programs. See Table 5.

First, it is important to assess nursing leaders' prior QI knowledge and training before the start of the course. QI training programs for nurse leaders and others employed in leadership positions should be structured to reflect participants' existing level of QI knowledge and experiences. While most of the nursing leaders in our study had prior QI experience, an accelerated or advanced QI training program could be designed to meet their level of QI experience and awareness. Alternatively, nursing leaders with less QI knowledge or experience could be provided with pre-training materials that allow them to adequately prepare for the QI training program. Like other studies of nursing leadership training ${ }^{[33]}$, the nursing leaders in our study reported gains in new QI knowledge, especially in use of QI tools (aim statement, metrics). Studies have suggested that nursing leadership practices greatly improve with new QI knowledge gained from training programs ${ }^{[34,35]}$.

Second, the course structure matters. Participants suggested several changes to the course structure, including lengthening the course and/or providing booster sessions. Also, the course should be interdisciplinary in nature and provide participants enough time and opportunity to work together to complete a QI project. Nursing leaders strongly expressed the benefit they received from working with non-nursing leaders in their QI training program. Third, the course curriculum should emphasize QI vocabulary and tools, as well as case studies and specific examples of QI cases. Nursing leaders preferred presentations and case studies because they were easy to understand and presented real-life scenarios of quality improvement initiatives. Also, the curriculum should be responsive to the learning style of participants and build off of different participant perspectives. Nursing leaders overwhelming appreciated the multidisciplinary nature of the QI course and the opportunity to interact with other senior leaders across the organization. 
The final recommendations emphasize the need for instructor feedback and involvement with participants during and after the completion of the QI training program. Instructors need to provide continued guidance to course participants about their QI project, during and after the project has been completed. A mentoring model might also be included, whereby participants with more QI knowledge can be paired with those with less QI knowledge and/or experience. Alternatively, nursing leaders who have completed the course may want to mentor participants new to the program. Finally, instructors should work with nursing leaders to assess their potential for implementing the QI projects into practice, providing tailored recommendations to ensure the sustainability of QI initiatives.

Table 5. Suggestions for Training Programs Targeting Nursing Leaders and Other Senior Leaders in Health Care Organizations

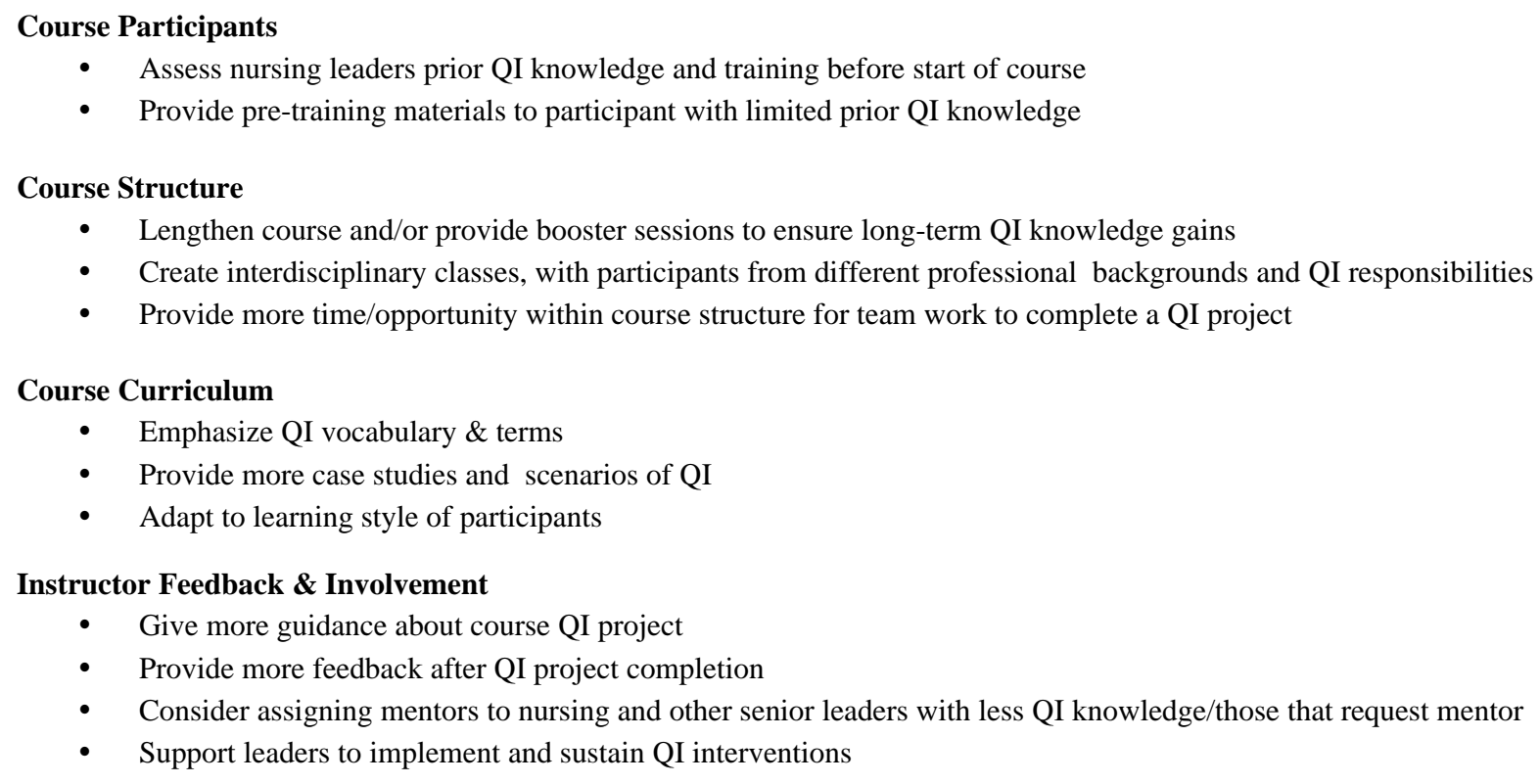

\section{Course Curriculum}

- $\quad$ Emphasize QI vocabulary \& terms

- $\quad$ Provide more case studies and scenarios of QI

- $\quad$ Adapt to learning style of participants

\section{Instructor Feedback \& Involvement}

- $\quad$ Give more guidance about course QI project

- $\quad$ Provide more feedback after QI project completion

- Consider assigning mentors to nursing and other senior leaders with less QI knowledge/those that request mentor

- $\quad$ Support leaders to implement and sustain QI interventions

Several limitations to this qualitative study should be considered. First, external validity may be limited by self-selection of the participants. Those who were contacted about the study volunteered to be interviewed and may be more representative of participants who had positive experiences with the Leadership course. Alternatively, we must acknowledge the possibility that those who were most unhappy with the course may have been more willing to be interviewed in order to express such grievances. This case is less likely, since overall, participants expressed high satisfaction with the course. In addition, recall bias may have played a role in participants' responses, since most interviews took place a year or later after they had finished the course. The time delay was purposeful in order to more accurately ascertain the longer term impact of the program from the perspective of the participants. Finally, though the sample size of the study was relatively small (29 out of a possible 545, or 5.3\%, senior leaders who took the QI training program), with qualitative research, the depth and quality of the information is paramount to a large sample size ${ }^{[36]}$.

The findings from this research provide strong evidence that nursing and other senior QI leadership training programs are important investments for health care organizations. While previous research into the effectiveness of such QI training programs is limited, this study contributes to understanding what elements are necessary to ensure positive patient outcomes. The experiences of nursing leaders in this QI training program were overall quite positive, contribute to improved QI learning, and reflect a strong interest in transferring QI knowledge into practice. This study indicates that nursing leaders can be effectively trained, become knowledgeable about QI terms and skills, and have the self-efficacy to support initiatives to improve outcomes. 
The leadership training program was one of several initiatives undertaken by the organization to promote quality improvement. In 2011, the University Health System Consortium (UHC) ranked EHC 10th among 101 academic medical centers, up from a ranking of 45th in earlier years. The Chief Quality and Medical Officer, William Bornstein, attributes this progress to system-wide collaboration and dedication to quality improvement. "The improvements we've achieved represent remarkable accomplishments that have been possible only through teamwork and collaboration...these improvements are not just numerical rankings. They also represent the progress we have made in caring for our patients.” ${ }^{[37]}$. The Leadership QI training course is one of the important investments EHC made, reaching over 500 organizational leaders over a three year period, to facilitate organizational change.

\section{Acknowledgements}

This study was sponsored by a grant from the Robert Wood Johnson Foundation. We thank Emory graduate students, Claire Feldman and Elizabeth Allen, for their assistance with data analysis. Additionally, we are grateful for the support from Richard S. Gitomer and Nathan O Spell, who provided access to the Leadership Course curriculum and participant roster.

\section{References}

[1] Batalden P, Davidoff F. Teaching quality improvement: The devil is in the details. JAMA. 2007; 298: 1059-1061. PMid:17785654 http://dx.doi.org/10.1001/jama.298.9.1059

[2] Canal DF, Torbeck L, Djuricich AM. Practice-based learning and improvement: A curriculum in continuous quality improvement for surgery residents. Arch Surg. 2007; 142: 479-483. PMid:17515491 http://dx.doi.org/10.1001/archsurg.142.5.479

[3] Ogrinc G, Headrick LA, Morrison LJ, Foster T. Teaching and assessing resident competence in practice-based learning and improvement. J Gen Intern Med. 2004; 19: 496-500. PMid:15109311 http://dx.doi.org/10.1111/j.1525-1497.2004.30102.x

[4] Greiner AC , Knebel E, eds. Health Professions Education: A Bridge to Quality. Washington, DC: National Academy Press; 2003.

[5] Holman WL, Allman RM, Sansom M, et al. Alabama coronary artery bypass grafting project: Results of a statewide quality improvement initiative. JAMA. 2001; 285: 3003-3010. PMid:11410099 http://dx.doi.org/10.1001/jama.285.23.3003

[6] Kiefe CI, Allison JJ, Williams OD, Person SD, Weaver MT, Weissman NW. Improving quality improvement using achievable benchmarks for physician feedback: A randomized controlled trial. JAMA. 2001; 285: 2871-2879. PMid:11401608 http://dx.doi.org/10.1001/jama.285.22.2871

[7] O’Connor GT, Plume SK, Olmstead EM, et al. A regional intervention to improve the hospital mortality associated with coronary artery bypass graft surgery: The northern new England cardiovascular disease study group. JAMA. 1996; 275 : $841-846$. PMid:8596221 http://dx.doi.org/10.1001/jama.1996.03530350023029

[8] Boonyasai RT, Windish DM, Chakraborti C, Feldman LS, Rubin HR, Bass EB. Effectiveness of teaching quality improvement to clinicians: A systematic review. JAMA. 2007; 298: 1023-1037. PMid:17785647 http://dx.doi.org/10.1001/jama.298.9.1023

[9] Walsh KE, Ettinger WH, Klugman RA. Physician quality officer: A new model for engaging physicians in quality improvement. Am J Med Qual. 2009; 24: 295-301. PMid:19487577 http://dx.doi.org/10.1177/1062860609336219

[10] Pronovost PJ, Miller MR, Wachter RM, Meyer GS. Perspective: Physician leadership in quality. Acad Med. 2009; 84: 1651-1656. PMid:19940567 http://dx.doi.org/10.1097/ACM.0b013e3181bce0ee

[11] Donaldson LJ. Safe high quality health care: Investing in tomorrow’s leaders. Qual Health Care. $2001 ; 10$ (Suppl 2): ii8-ii12. PMid:11700373 http://dx.doi.org/10.1136/qhc.0100008

[12] Rask KJ, Gittomer RS, Spell NO 3rd, et al. A two-pronged quality improvement training program for leaders and frontline staff. Jt Comm J Qual Patient Saf. 2011; 37: 147-153. PMid:21500714

[13] O’Connor M, Walker JK. The dynamics of curriculum design, evaluation, and revisions: Quality improvement in leadership development. Nurs Adm Q. 2003; 27: 290-296. PMid:14649020

[14] Kim CS, Lukela MP, Parekh VI, et al. Teaching internal medicine residents quality improvement and patient safety: A lean thinking approach. Am J Med Qual. 2010; 25: 211-217. PMid:20357082 http://dx.doi.org/10.1177/1062860609357466

[15] Frey K, Edwards F, Altman K, Spahr N, Gorman RS. The 'collaborative care' curriculum: An educational model addressing key ACGME core competencies in primary care residency training. Med Educ. 2003; 37: 786-789. PMid:12950941 http://dx.doi.org/10.1046/j.1365-2923.2003.01598.x 
[16] O’Connor ES, Mahvi DM, Foley EF, Lund D, McDonald R. Developing a practice-based learning and improvement curriculum for an academic general surgery residency. J Am Coll Surg. 2010; 210: 411-417. PMid:20347732 http://dx.doi.org/10.1016/j.jamcollsurg.2010.01.017

[17] Bernabeo EC, Conforti LN, Holmboe ES. The impact of a preventive cardiology quality improvement intervention on residents and clinics: A qualitative exploration. Am J Med Qual. 2009; 24: 99-107. PMid:19233945 http://dx.doi.org/10.1177/1062860608330826

[18] Ogrinc G, Headrick LA, Mutha S, Coleman MT, O’Donnell J, Miles PV. A framework for teaching medical students and residents about practice-based learning and improvement, synthesized from a literature review. Acad Med. 2003; 78: 748-756. PMid:12857698 http://dx.doi.org/10.1097/00001888-200307000-00019

[19] Ackerly, DC, Sangvai, DG, Udayakumar, K, Shah, BR, Kalman, NS, Cho, AH, Schulman, KA, Fulerson, WJ, Dzau, VJ. Training the next generation of physician-executives: an innovative residency pathway in management and leadership. Acad Med. 2011; 86: 575-579. PMid:21436663 http://dx.doi.org/10.1097/ACM.0b013e318212e51b

[20] Gagliano NJ, Ferris T, Colton D, Dubitzky A, Hefferman J, Torchiana D. A physician leadership development program at an academic medical center. Qual Manag Health Care. 2010; 19: 231-238. PMid:20588142

[21] Wurster AB, Pearson K, Sonnad SS, Mullen JL, Kaiser LR. The patient safety leadership academy at the University of Pennsylvania: The first cohort's learning experience. Qual Manag Health Care. 2007; 16: 166-173. PMid:17426615

[22] Walrath JM, Muganlinskaya N, Shepherd M, et al. Interdisciplinary medical, nursing, and administrator education in practice: The Johns Hopkins experience. Acad Med. 2006; 81: 744-748. PMid:16868432 http://dx.doi.org/10.1097/00001888-200608000-00013

[23] DelliFraine J, Langabeer J, King B. Quality improvement practices in academic emergency medicine: Perspectives from the chairs. West J Emerg Med. 2010; 11: 479-485. PMid:21293770

[24] Korschun HW, Redding D, Teal GL, Johns MM. Realizing the vision of leadership development in an academic health center: The woodruff leadership academy. Acad Med. 2007; 82: 264-271. PMid:17327716 http://dx.doi.org/10.1097/ACM.0b013e31803078b5

[25] Suhayda R, Miller JM. Optimizing evaluation of nursing education programs. Nurse Educ. 2006; 31: 200-206. http://dx.doi.org/10.1097/00006223-200609000-00005

[26] Richards L. Handling Qualitative Data: A Practical Guide. 2nd ed. Thousand Oaks, CA: Sage Publications Inc.; 2009.

[27] Strauss AL, Corbin JM. Basics of Qualitative Research: Techniques and Procedures for Developing Grounded Theory. 2nd ed. Thousand Oaks, CA: Sage Publications Inc.1998.

[28] Charmaz K. Constructing Grounded Theory: A Practical Guide through Qualitative Analysis. Thousand Oaks, CA: Sage Publications Inc. 2006.

[29] Glaser BG, Strauss AL. The Discovery of Grounded Theory: Strategies for Qualitative Research. Hawthorne, NY: Aldine De Gruyter; 1967.

[30] Lingard L, Albert M, Levinson W. Grounded theory, mixed methods, and action research. BMJ. 2008; 337: a567. PMid:18687728 http://dx.doi.org/10.1136/bmj.39602.690162.47

[31] MAXQDA [computer program] Version 10. Marburg, Germany: VERBI GmbH. 2010.

[32] Armstrong, G, Headrick, L, Madigosky, W, Ogrinc, G. Designing Education to Improve Care. Joint Commission J on Quality \& Patient Safety. 38(1): 5-14. PMid:22324186

[33] Wicker, TL. Self report of nursing leadership practice after completion of training. University of Arizona, doctoral thesis. 2008.

[34] Ceraso, M, Gruebling, K, Layde, P, Remington, P, Hill, B, Morzinski, J, Ore, P. Evaluating Community-Based Public Health Leadership Training. J Public Health Management Practice. 2011; 17(4): 344-349. PMid:21617410

[35] Duygulu, S and Kublah, G. Transformational leadership training programme for charge nurses. J Advanced Nursing. 67(3): 633-642. PMid:21077934 http://dx.doi.org/10.1111/j.1365-2648.2010.05507.x

[36] Crouch M, McKenzie H. The logic of small samples in interview-based qualitative research. Soc Sci Inf. 2006; 45: 483-499. http://dx.doi.org/10.1177/0539018406069584

[37] Skelly, LM. Emory hospitals make leaps in university healthsystem consortium national quality rankings. University News. September 23, 2011. 